\title{
COMMUNICATIONS: THE WAY OF TRANSMITTING MESSAGES AND COMMUNICATION SKILL
}

Communication is woven in almost all branches of economy and art, either as a separate skill or as one of the segments in the interdisciplinary approach. It is also a demonstrative and irreplaceable link in the study of various disciplines of management and marketing, as well as in public relations. This paper, after a short basic characteristic of communication, gives detailed analysis about the way of transmitting messages and communication skill. Special attention was paid to the understanding of the sender and the recipient, through the process of coding and decoding of the information. At the end, a communication network established by combining verbal and non-verbal communication systems is analyzed.

Key words: communication, coding, noise, speech, rhetoric, information

\section{Basic characteristics of communication}

Communication is a word of Latin origin. It is derived from a verb meaning "to make common, to report", while the noun meant "community, circulation, report".

The very meaning of the words "communicare" and "communicatio", which lead to the term communication, indicates that the essence of communication is in fact a transition from the individual to the collective, a transition which contributes to establishing a community and social behavior.

Communication (by Grinberg, 1998) can also be defined as a process through which a person, a group or an organization (sender) transmits a kind of information (message) to another person, group or organization (recipient). This definition is graphically shown in Figure 1. The diagram helps to better perceive the various phases in the process of communication.

A communication process starts when one party has an idea which it wants to transmit to another party, both parties being an individual, a group or a whole organization.

The sender's task is to transform that idea into a form which can be transmitted to the recipient who will be able to understand it. This process is called the coding process, and it represents translating an idea into a form, e.g. written or spoken language, which the recipient can recognize.

This process is of primary significance if communication should be clear.

When a message has been coded, it is ready to be transmitted through one or more channels of communication to the desired recipient, along the ways that information travels, through a tele-

* Zoran Čekerevac, Slobodan Ristić

Railway College Belgrade, www.vzs.edu.yu, zoran.cekerevac@hotmail.com phone line, television or radio signals, by mail or by Internet...The form of coding largely depends on how the information is to be transmitted; however, no matter which channel is used, it is important to transmit the coded message to the desired recipient correctly.

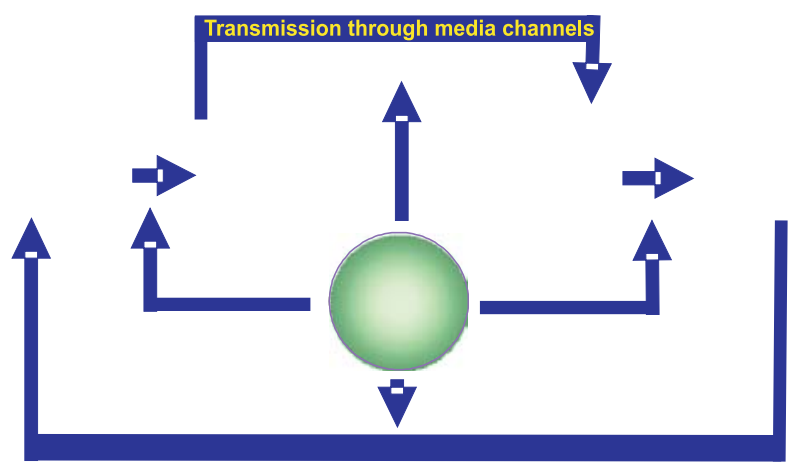

Fig. 1 Communication process

After receiving a message, the recipient starts a decoding process, i.e. returns the message to the form of the sender's original idea. Various sub-processes may be included in this, such as understanding spoken or written words, interpreting facial expressions and the like.

If the recipient has decoded the sender's message correctly, he/she will understand the idea which the sender wanted to transmit. The ability to understand and interpret information is not perfect. As in the case of coding, limitations in the sense of ability to decode some information represent a potential weakness in a communication process. A limitation can be an unclear message as well. 
After the message has been finally decoded, the process can be continued by the recipient transmitting a new message to the first sender. This part of the process is called FEEDBACK - and it represents the knowledge of what influence the message has had on the recipient. Having received the feedback, the sender is able to see whether his messages have been understood properly. At the same time, the feedback may convince the recipient that the sender cares for his/her opinion. Once it has been received, the feedback may provoke a new idea with the sender, which may start a new cycle of transmitting information.

In spite of obvious simplicity of the communication process, it rarely functions as ideally as it has been shown here. There are many potential obstacles to effective communication. The factors which damage the clarity of a message are called noise and they can decrease the effectiveness of communication. Noise may be either badly coded (e.g. unclearly written) or badly decoded (e.g. unheard) messages, and also the channels of communication which are full of statics (e.g. the recipient's attention is diverted from the basic message), as well as some other factors (e.g. time pressure, organizational policy...). Noise may cause a distortion of information which is transmitted from one person to another.

\section{The way of transmitting messages and communication skill}

One of the key purposes of organizing communication is to direct an action, i.e. to make other people behave in a desired way. In order to achieve the aim, the so-called communication bridges are established and obstacles and barriers are overcome. For this purpose, techniques and methods of communication are used and practiced, within different fields and spheres of business environment and social life.

The way of communicating is a skill which can be learnt, practiced and improved. As it has a tendency to create a human, goodquality and esthetic element, communication may also have artistic characteristics. The skill to communicate represents an activity of the spirit which is changed and transformed in time and by experience. It simultaneously points to the art of living, the beauty of a relationship with people, and raises the culture of communication to a higher artistic level.

It may be said that communication is woven in almost all branches of economy and art, either as a separate skill or as one of the segments in the interdisciplinary approach. It is also a demonstrative and irreplaceable link in the study of various disciplines of management and marketing, as well as in public relations.

At the moment of establishing any kind of relation, the following questions should be asked:

- Why do we communicate?

- Who do we communicate with?
- How to be accessible and flexible in that process?

- How to be polite, tactical and patient all the time?

- How to make a profound impression on other people? ${ }^{1)}$

The moment of transmitting information is the most significant in communication. Information is a notice, an announcement, or a fact. It also represents the way of organizing, selecting and creating a certain matter. Information should be reliable, checked, controlled, as well as dynamic. It is not eternal but susceptible to changes. The process of information flow does not consist only of emitting, i.e. transmitting information, but it also requires receiving and decoding a certain message properly, as well as feedback. There is no passive spectator in this process, even if one party in the dialogue is more active in the verbal sense.

In the process of information flow, one party is a sender or transmitter of information and the other is an active recipient. The interaction includes transmitting a message and understanding it properly. Whether the recipient will take and understand a message depends on its contents, the choice of arranged signals, and on the way of communicating the form (the functioning of the system of verbal and non-verbal communication). Public information and speech are sometimes quite wrongly connected only with mass media communication, which narrows the field of action for these categories, and frees a person from responsibility in individual components. Responsibility is equally important in contacts with only one person and when performing in front of a large auditorium. In order to transmit messages and information of different sorts, no matter what type of communication is in question, established signals, i.e. terms, must be chosen.

Public speech is different from everyday speech, because it requires a special application of oratory. Oratory in a modern sense is a complex aspect of verbal communication: it is all-inclusive, informative, argumentative, competent and dynamic. The communicative dynamism is reflected in the way of transmitting messages. In the transmission of information, parts of a statement can be noticed and codes must be chosen, which will lead to revealing the meaning of a message during an information exchange. In order that both participants in a conversation should understand each other, thoughts must be formed in a simple way into an understandable statement by visualizing an idea.

Without entering the theory of meaning, we will only indicate here how to influence recipients of messages in the most appropriate and objective way within a certain communication and behavior. The communicator - speaker - has a complex task: how to transmit a message and meaning in a desired context to the recipient. $\mathrm{He} / \mathrm{she}$ ought to find a system of signs which will correspond to the broadest public and contribute to a clear, concrete, real and objective delivery of a message. Feedback shows the degree of understanding.

The outline of a communication process is shown in Figure 2.

\footnotetext{
${ }^{1)}$ M. Marković: Poslovna komunikacija, CLIO, Beograd 2003
} 


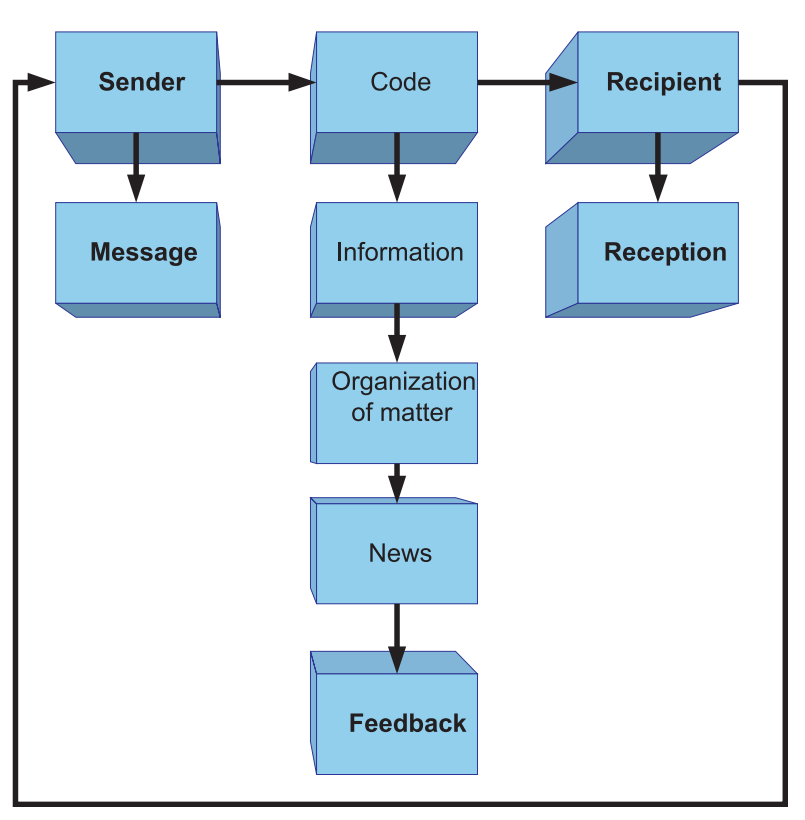

Fig. 2 Communication process with circular flow

Sometimes messages happen to be insufficiently understood, or completely misunderstood and misinterpreted, which causes a communication tension, misunderstanding, and even a conflict. Thus, it is not only important to transmit certain information and ideas, i.e. to pay attention to the contents of a message; the way of transmitting those messages is of crucial significance.

That is why the sentence: "I do not understand" is often heard. It is a good sign of warning which must not be ignored and rejected without thinking. This sentence also offers very important information. It represents a communication bridge for a very skilful communicator, because it is a clear and sincere statement (information) which cannot and must not be ignored. The communicator must try to explain the information, to choose proper terms for the desired idea, and to find another, better and more effective way to transmit the message to the other participant in the communication. Another sentence which is usually heard is: "I do not agree!". Therefore we can say that there are innumerable ways of transmitting and receiving messages. In future, the above mentioned statement could be replaced by another: "I see it in a different way!”. The way of forming and transmitting a message contributes to understanding it.

We should consider all levels of meaning which can be noticed in a clear message (text, dialogue, gesture, or voice). It is understandable that there is also a wish and intention to influence listeners or partners in a conversation with a subtext of certain implied messages which are transmitted, and not only with a direct statement. It is particularly noticeable in the sphere of art and political life. Certain variants should therefore be found to make "hidden" messages clear and understandable, and to lead their decoding to understanding them.

Public communication skill does not consist of the quantity of offered information but of the multitude of ideas and matter cre- ation. Communication is not an exchange of sentences but an exchange of ideas formed in a conversation. Speech expression is an important quality in a verbal communication. There are also many signals in the sense of body expressiveness and movements meaning, such as mimic, manual and situational movements, the position of a body in space, etc. The activity in relation to the listener or partner in a conversation can be noticed, first of all, through the opening to the partner or withdrawing from him/her.

Communication skill implies:

- speed;

- economy;

- organization;

- control;

- selectivity;

- trust building.

It is not enough just to have a good idea. It should, in a certain way, be transmitted to the recipient of a message for the purpose of communication. A speech shows the way of the speaker's thinking. People often make mistakes trying to use many words to explain an idea. It is much more important to find adequate images and sounds, i.e. words transformed into understandable and interesting visual impressions and sounds. In that way, the monotony of the sequencing of words in a sentence is broken and the speech can be perceived as a whole. A theoretical discussion and program presentation may seem abstract. Businessmen have no confidence in this method; they demand examples and evidence from practice. An idea will be best presented if it is shown in a simple and practical way - visually and auditory.

Mastering the communication skill may be realized in the following phases:

a) observing and noticing certain characteristics of people and things;

b) classifying these characteristics into groups: important and unimportant; selectively noticing certain features necessary for business communication;

c) adapting behavior, that is selecting certain communicative skills necessary for successful business operations;

d) noticing the reaction of the partner in a conversation;

e) retaining, transforming or completely changing a certain behavior. It should be mentioned that a change in behavior is a skill and not flattering, i.e. giving up or deviating from own attitudes. A change in behavior means adapting to the partner ("walking with him/her"), improvising in looking for various possibilities for a contact, reaching an agreement or a compromise. A change in behavior shows certainty, self-confidence, ability to control a whole process, and a complete domination;

f) noticing the moment of adaptation in the partner in a dialogue, as an attempt to establish bridges in a communication and to show a wish to understand. This moment represents the communicator's first-class skill, for example, in the course of complex negotiations;

g) noticing own mistakes and consequences which those mistakes have or may have on the process as a whole; attempting 
to eliminate the mistake without apologizing, but with a change in behavior. To the partner in a conversation, it will be the best sign that tactics has been changed or that there is awareness of a wrong method selected which should be changed or adapted;

h) scoring with no triumph - no one should show that he/she is the winner or has a certain advantage after the negotiations. Confidence and competence should not be proved by enjoying the achieved success and advantage - it goes without saying, because it is a part of the job and professional responsibility for a business operation. ${ }^{2}$

What causes a misunderstanding? There are many reasons, among which are the following:

- message is not transmitted in an understandable way - problems with terminology;

- conflict of many different ideas - unfocused thinking;

- too much information (overburdening);

- lack of information;

- not understanding or misunderstanding a message

- not knowing the partner in a conversation;

- noise, disturbance;

- absent-mindedness, being not concentrated;

- deliberate disinformation;

- suppressing, hushing up a misunderstanding.

If a problem turns up in communication, it must be:

- identified and defined, not ignored;

- considered;

- solved. two types of clients:

a) clients who are ready to be informed and to satisfy their needs. Cheerful, pleasant and energetic tones are predominant in a conversation with this type of clients;

b) clients who deliberately use a form of aggressive behavior to get an advantage in communication, to impose their own opinion and ideas.

The signs of non-verbal communication are a good indicator of which type of clients is in question, and if they are noticed in

A good relation between the partners in a conversation may be established in the following way:

a) listening to the partner and making deliberate pauses during the speech;

b) applying the technique of cross-examination;

c) ignoring the personal moment and exaggerated emotional reaction (in the case of an aggressive and possessive client);

d) applying a quiet, central and assured tone;
In various forms of social communication, there are generally time they can give the speaker a certain psychological advantage.

e) applying an active relation, without withdrawing, in order to build up a solid business contact;

f) appearing self-assured in the sense of:

- body attitude (straight spine),

- looking at the partner,

- calm and confident movements,

- well-balanced movement in space;

g) reaching an agreement or a compromise.

The negotiations with a difficult client may be successfully ended only if the speaker is sure of himself/herself, if he/she is consistent with his/her personal viewpoints and arranges well the time in which he/she will say everything that is necessary in a precise, clear and concise way.

Contacts are established by creating a pleasant atmosphere for conversation, through an activity directed to the listener or partner in the conversation, and the motivation to reach a mutual viewpoint, while respecting the partner's opinion.

Sometimes a speech - words - cannot express primary emotions. The verbal expression of messages may seem too direct and exclusive, particularly when we have to break the news which is not affirmative. Therefore, as a very important system of signs, voice expression and body language (movement, gesture, position, and attitude) can be used to transmit a particular message. Body language allows a certain distance, and it is less likely that the partner in a conversation will be hurt by this way of rejection. Non-verbal communication in a positive way draws attention from a basic, simple and simplified verbal expression to a multi-layered expression.

A communication network is established by combining verbal and non-verbal communication systems. It includes several segments:

a) The speaker's intention - motivation for a conversation or speech. Even Aristotle recognized three types of technical methods of convincing:

- the first is achieved by the speaker's character,

- the second is achieved by the mood created in the listener,

- the third is achieved by the very speech, and the speech should contain three parts:

- sources from which methods for convincing are derived,

- the way of making a speech (discussion, style, composing and giving a speech),

- the arrangement of the parts of a speech; ${ }^{3)}$

b) The dynamic movement of a verbal act - can be followed through an analysis of a conversation. In the contents of every conversation there is a sentence or a part of sentence which is particularly emphasized semantically. It is the most important point in a dialogue - the argument or the focus of a verbal act;

\footnotetext{
3) M. Marinović, Poslovna komunikacija sa poslovnim bontonom, pp. 17-21, CLIO, Beograd 2003

3) 4 Aristotel, Retorika 1; Retorika 3; Novi Sad 1997
} 
c) The process of listening - psychological, acoustic and cognitive elements participate in this complex process equally;

d) Non-verbal communication which represents a complex system and can be viewed as a single movement and a series of movements - gestures, and as a pose, the position of a body in space, an arrangement of groups in space, etc.

\section{Conclusion}

The key purpose of communication is to direct an action, i.e. to make other people behave in a desired way. During that process, communication bridges are established, and obstacles and barriers are overcome. For that purpose, various techniques and methods of communication are used and practiced, keeping in mind a variety of fields, spheres of business environment and social life. The way of communicating is a skill which can be learnt, practiced and improved.

The most important moment in communication of any kind is the preparation which demands creating, opening and completing data bases, and then making a strategic and operational plan.
Thus, these plans depend on the essence of an analysis. A situational analysis is a very important moment and consists of the correct answers to the questions: Who communicates? How much/when/where/why, and for what purpose does he/she communicate? The success of a communication act depends on the degree of precision within the answers to the asked questions. That is why it is important to know who the person someone is talking to is (sex, age, profession, status, etc.), how many persons will be present at a business meeting, the meeting place - what it is like, and how large the room in which the meeting will take place is, how much time is available for a presentation, dialogue and listening. Any person that wants to be a good communicator and to master the skill of communication must try to find answers to these questions.

They reveal and show the purpose of a compact process - why we communicate, and particularly what our goal is.

Each communication, in order to be successful, must be carefully and well prepared. Whether it will be successful depends on the communicator, the listener, as well as on the "noise".

\section{References}

[1] ARISTOTEL: Rhetoric 1, Retorika 3; Novi Sad, 1997

[2] CEKEREVAC, Z., RISTIC, S.: The Concept, Traits and Characteristics of the Director-Organizer-Manager Personality (In Russian), In: LXV International Scientific Conference: The Issues and the Prospective of the Railway Transport Development, In: Dniepropetrovsk National University of Railway Transport (DIIT) named after Academician V. Lazaryan, Dniepropetrovsk, May 2005

[3] DVOŘÁK, Z.: The Possibility of using the geographical information systems in the pipe transport of Military Forces of Slovakia, In: Zborník 11. Scientific Conference ŽU, pp. 121-126, Žilina, 2003,

[4] GRINBERG, J., Baron, R.: Behavior in Organisation (in Serbian), In: Prentice Hall, 1995, In: Zelnid, Belgrade 1998,

[5] MARINOVIĆ, M.: Business Communication with Business Bon-Ton (in Serbian), In: CLIO, pp. 17-21, Belgrade 2003

[6] MARKOVIĆ, M.: Business Communication (in Serbian), In: CLIO, Beograd 2003., In: CLIO, Beograd 2003. 